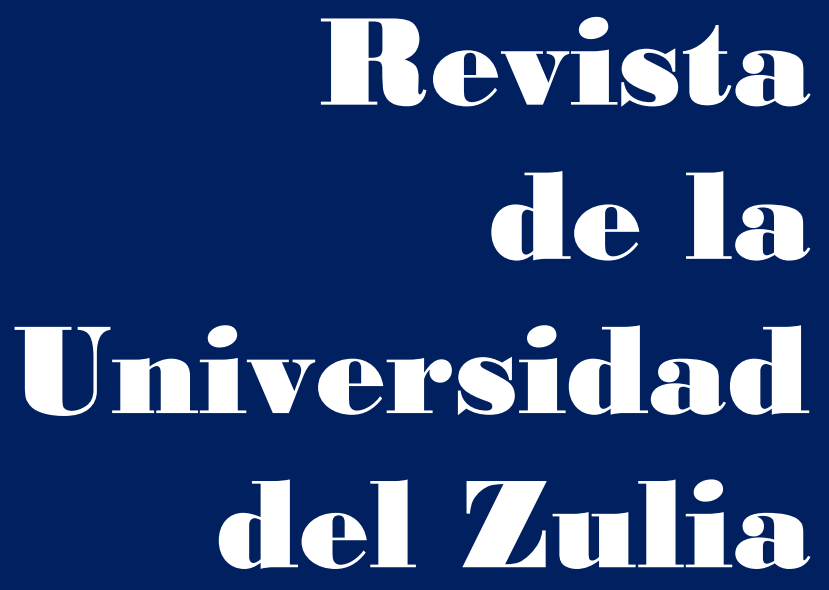

Fundada en 1947

por el Dr. Jesús Enrique Lossada

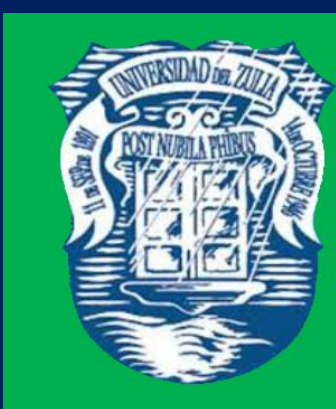

Ciencias del

Agred

Ingemieria

y Teenología
Añต 12 No 32

Enero - Abril 2021

Tercera Época

Maracailbo-Venezuela 
REVISTA DE LA UNIVERSIDAD DEL ZULIA. 3épeca. Año $12 \mathrm{~N}^{\circ}$ 32, 2021

Jorge J. Villasmil Espinoza/// Implicaciones de la inteligencia artificial para la humanidad, 4-6 DOI: http://dx.doi.org/10.46925//rdluz.32.01

\title{
Implicaciones de la inteligencia artificial para la humanidad
}

\author{
Jorge J. Villasmil Espinoza *
}

A menudo se acepta que la inteligencia artificial AI, tiene una fuerza inusitada para transformar la civilización humana en su conjunto o, como bien señala Harari Noah (2015), para convertir a la persona humana en una entidad diferente capaz de integrar continuamente, en su esencia y existencia, los aportes de la ingeniaría genética, la nanorrobótica y la AI para impulsar su proceso evolutivo y reducir significativamente los limites materiales y simbólicos de sus capacidades. ¿La IA viene a complementar la dignidad humana? A ciencia cierto lo único que está claro por el momento es que en el futuro próximo esta tecnología rebasará a la ciencia ficción.

Tal como indican Brito Paredes, Villavicencio Aguilar y Sánchez Saca (2019), la IA es un:

...tipo particular de inteligencia tecnológica que, aunque tiene su punto de inicio en las personas, que es su artífice y causa primaria, puede funcionar con independencia y autonomía frente a la misma, llegando incluso a superar en muchos aspectos las capacidades cognitivas y procedimentales de la humanidad. (2019: 261).

En la definición citada, se destaca la independencia y la autonomía de la IA y su capacidad para superar en muchos aspectos las habilidades y destrezas (cognitivas y procedimentales) de las personas. Esta realidad no tiene que ser --por sí misma-- problemática y a la postre todo dependerá de los usos y abusos que se haga de esta tecnología que en su doble manifestación de hardware y software, ya está presente en nuestra vida cotidiana, en los motores de búsqueda de la web que vienen a anticipar nuestras preferencias en el acceso a la información, o también en los algoritmos de búsqueda de las plataformas de streaming que, como Netflix, nos muestra contenidos acordes con nuestros gustos, entre otros.

* Doctor en Ciencia Política, profesor titular en la Universidad del Zulia. Editor responsable de Cuestiones Políticas. E-mail: jvillasmil52@hotmail.com; jvillasmil@fcjp.luz.edu.ve ORCID: https://orcid.org/0000-0003-0791-3331. 
REVISTA DE LA UNIVERSIDAD DEL ZULIA. 3ㄹépoca. Año $12 \mathrm{~N}^{\circ}$ 32, 2021 Jorge J. Villasmil Espinoza/// Implicaciones de la inteligencia artificial para la humanidad, 4-6 DOI: http://dx.doi.org/10.46925//rdluz.32.01

También podríamos suponer que en las próximas décadas muchas actividades laborales, intelectuales y de trabajo físico, van a ser desarrolladas por robots inteligentes de forma satisfactoria incrementando en su decurso el desarrollo sostenible y el tiempo libre de las personas para el esparcimiento y la formación integral. En un mundo así, incluso pudiéramos suponer que la IA pudiera venir a remediar las crisis de la democracia, impulsada en buena medida por gobiernos corruptos e ineficientes que actúan en función de interés particulares que en nada tienen que ver con el logro del bienestar social.

En este contexto, muchas de las grandes decisiones políticas en materia de gestión de conflictos, administración de recursos y organización de comunidades, pueden ser tomadas por ordenadores cuánticos con base a criterios técnicos prestablecidos por programadores, democráticamente electos, que actúen bajo la filosofía del gobierno abierto y la sociedad del conocimiento, sin necesariamente tener ninguna militancia partidista. Seria en buena medida el gobierno de la ciencia o el advenimiento de una nueva tecnocracia postmoderna.

De hecho, la construcción de un nuevo contrato social (Calvano, 2019; Márquez, 2020) que venga a subsanar lo que en trabajos anteriores he definido como la fragilidad de las civilizaciones humanas (Villasmil Espinoza, 2020), configurada por fenómenos geopolíticos internacionales como el calentamiento global, la pobreza, la inequidad de género o las violaciones sistemáticas de los derecho humanos impulsadas por estados autoritarios, tienen en la IA una herramienta transversal con mucho que aportar en el plano político, económico, social y cultural, cuando se busca construir gobernabilidad y gobernanza desde perspectivas científicas que trasciendan los dogmas ideológicos y los prejuicios partidarios.

No obstante, no debe suponerse que todo lo concerniente a la IA es siempre bueno y constructivo y que, por lo tanto, debe asumirse acríticamente sin el desarrollo de un debate polifónico capaz de develar todas las aristas del fenómeno, de cara a potenciar su conocimiento profundo y la reflexión sistemática al respecto. En este sentido, se justifican preguntas como: ¿Puede el uso generalizado de la IA potenciar los mecanismo formales e informales de control social, tal como presagia la polémica serie Black Mirror? ¿Una organización social dirigida por "maquinas inteligentes" es un ordenamiento reprochable desde todo punto de vista por su carácter deshumanizado? Obviamente, que la respuesta a estas y otras preguntas similares 
REVISTA DE LA UNIVERSIDAD DEL ZULIA. 3épeca. Año $12 \mathrm{~N}^{\circ}$ 32, 2021

Jorge J. Villasmil Espinoza/// Implicaciones de la inteligencia artificial para la humanidad, 4-6

DOI: http://dx.doi.org/10.46925//rdluz.32.01

sobrepasa los límites de estas reflexiones, pero, incitan a futuros investigadores a seguir indagando en las implicaciones del tema.

La Revista de la Universidad del Zulia es uno de los muchos espacios editoriales donde estos temas trascendentales son analizados, con miras a ofrecer perspectivas en torno al desarrollo de la humanidad. En su edición 32 (Tercera Época), encontramos un conjunto de artículos relacionados con las áreas de Ciencias del Agro, Ingeniería y Tecnología. Nos complace que, luego de 74 años de recorrido, la Revista de la Universidad del Zulia siga siendo parte importante del quehacer institucional de la Universidad del Zulia.

\section{Referencias}

Brito Paredes, P., Villavicencio Aguilar, C., \& Sánchez Saca, P. (2019). Reflexiones sobre posibles conflictos entre la inteligencia artificial y el futuro de la sociedad. Revista de la Universidad del Zulia, 10 (28), 260-280.

Calvano Cabezas, L. (2019). Apuntes sobre los desafíos que entraña el nuevo contrato social para Colombia en tiempos del postconflicto. Cuestiones Políticas, 14-29.

Harari Noah, Y. (2015). Homo Deus Breve historia del mañana. Barcelona: Debate.

Márquez Ramírez, Jesús Alberto (2020). Aportes de la Modernidad al desarrollo de la teoría democrática, Revista Latinoamericana de Difusión Científica, 2 (2), 69-92. DOI: https://doi.org/10.38186/difcie.22.06

Villasmil Espinoza, J. (2020). La fragilidad de la civilización humana. Cuestiones Políticas, 10-14. 